\title{
Patricio de Navascués
}

Director del Instituto de Filología Clásica y Oriental San Justino.

Profesor de Teología Patrística de la Facultad de Teología de San Dámaso (Madrid)

\section{El sustrato filosófico de la obra de Eustacio de Antioquía}

\section{INTRODUCCIÓN}

He de decir, de entrada, que el personaje de Eustacio de Antioquía, obispo, activo antes y después del concilio de Nicea del año 325, atrae mi atención por varios motivos. Me topé con él a la hora de elaborar mi tesis doctoral sobre Pablo de Samosata y siempre me suscitaba gran interés ver hasta qué punto podían ser semejantes en determinados planteamientos, dos obispos, de Antioquía los dos, separados por tan solo medio siglo aproximadamente, de los cuales uno terminó por convertirse en uno de los prototipos de hereje y el otro engrosó la lista de los santos padres nicenos.

Por otro lado, Eustacio de Antioquía, considerado en sí mismo, representa una línea muy interesante de reflexión. Es un contrapeso fuerte, tal vez el más preparado de la época, para frenar los excesos de la tradición origeniana y alejandrina. Sin llegar a los planteamientos monarquianos de Marcelo de Ancira ni participar de la falta de preparación que, a menudo, caracterizó las intervenciones del occidente antiarriano de primera hora, Eustacio se alza como una figura de equilibrio. Fuera o no fuera verdad que presidió y dirigió las discusiones del sínodo de Nicea, el hecho de que, en el peor de los casos, tal noticia pudiera haber sido fabricada, habla por sí sola del prestigio del que gozó en vida este Padre de la Iglesia.

Por esto mismo me causa, en cierto modo, perplejidad el abandono del que ha sido objeto su obra por parte de la crítica moderna. Es verdad que el conjunto de su obra, salvo en el caso de la interpretación del encuentro entre Saúl y Samuel evocado por la pitonisa, no nos ha llegado más que fragmentariamente. Pero los fragmentos de Apolinar, Nestorio y otros, aun siendo fragmentos, suscitaron entre los investigadores mucha mayor atracción que estos de Eustacio.

En cualquier caso, la situación de hoy es privilegiada con respecto a décadas pasadas. Contamos efectivamente con una edición crítica notablemente editada por José H. Declerck, Eustathii Antiocheni, Patris Nicaeni, opera quae supersunt omnia [Corpus Christianorum Series Graeca 51], Turnhout 2002. (Desde ahora me referiré a ella como Eustathii Antiocheni opera omnia, añadiendo el número de página o páginas después). En ella se da cuenta detalladamente de la tradición manuscrita de la obra supérstite de Eustacio y se presentan los textos en su lengua original (griegos en su mayoría, aunque también nos han llegado en siríaco y latín), además de avanzar claves 
interpretativas acerca del pensamiento de Eustacio (1). Este buen instrumento debería suponer un estímulo para que Eustacio ocupe el lugar que merece en la historia del dogma, en la controversia arriana, en la tradición llamada antioquena.

\section{LA FIGURA DE EUSTACIO DE ANTIOQUÍA}

Poco sabemos acerca de la biografía de Eustacio de Antioquía. Poco y controvertido. Las fuentes antiguas son avaras a la hora de desprender más datos (2).

Eustacio, al que las fuentes antiguas nos presentan como confesor (debido, sin duda, a las persecuciones de Diocleciano o de sus sucesores), hubo de nacer en el último cuarto del s. III, parece que en Sida de Panfilia (Asia Menor). Eustacio habría de ocupar la prestigiosa sede de Antioquía, aunque antes parece que se estrenó como obispo en la Iglesia de Berea (hoy Alepo, Siria). En Antioquía sucedió, según cuentan algunas fuentes, al obispo de signo arriano Paulino, es decir, un obipo de planteamientos muy distintos al suyo (3). La sede antioquena debió de ser escenario de este tipo de luchas desde la época inmediatamente anterior a Pablo de Samosata hasta los tiempos de Eustacio, por lo que la poca información que nos ha llegado deja entrever (4). Esto habría de desembocar después en el denominado cisma de Antioquía, que laceró esta Iglesia (y la Iglesia universal) durante el s. IV y buena parte del s. V.

Como obispo de Antioquía, Eustacio participó en el sínodo niceno, después del cual continuaría su misión pastoral y su obra teológica, hasta donde le permitieron los ataques del partido de tendencia filoarriana, ataques que le valieron la deposición y el destierro. La vida de nuestro personaje se esfuma a partir de entonces. Para algunos debió de morir antes del año 337, para otros que conceden credibilidad a unos fragmentos de una supuesta obra dirigida contra Fotino, debería de estar vivo aún en torno a los años 360 .

Acerca de su obra (5), se suele presentar a Eustacio como a un personaje que habría experimentado una evolución a la hora de hacer frente a los arrianos, subrayando a partir de entonces, cada vez con más ahínco, la impasibilidad del Logos, no afectada por la encarnación de Cristo. Creo que, en su lugar, ya he mostrado cómo en esto Eustacio no hacía sino continuar -aunque no en todo- planteamientos muy parecidos a los sostenidos por su predecesor en la sede, Pablo de Samosata, contra su oponente Malquión en torno a los años 260 (6).

(1) Es realmente compleja la edición de un autor de este estilo porque uno de los primeros problemas con que se enfrenta el editor es el de saber discernir entre las fuentes auténticas y las falsas. Acerca de este punto, no comparto en todo las conclusiones de J.H. Declerck, pero es un punto que desborda los límites de esta ponencia y sobre el que espero poder escribir en breve.

(2) Cf. Eustathii opera omnia, pp. CCCLXXXVI-CCCXCII.

(3) Cf. R. W. Burgess, Studies in Eusebian and Post-eusebian Chronography, Stuttgart 1999.

(4) La sucesión desde mediados del s. III es Demetriano, Pablo de Samosata, Domno, hijo de Demetriano, y después Timeo, Cirilo, Tirano, Bitalio, Filogonio, Paulino y Eustacio, tal como informa Eusebio y la Continuatio Antiochiensis Eusebii.

(5) Cf. el análisis de los fragmentos auténticos en Eustathii opera omnia, pp. CCCXCIV-CCCCXVI. No comparto -como ya he señalado- todas las opciones de J.H. Declerck, pero ofrece buenos elementos en este repaso.

(6) Cf. P. de Navascués, Pablo de Samosata y sus adversarios, Roma 2004, pp. 426-430. 
En esta disertación me propongo acercarme a lo que pudieron ser las líneas maestras filosóficas de las posiciones teológicas de Eustacio, prescindiendo, por tanto, del aspecto quizás de mayor relieve en la obra de un teólogo y pastor -el estrictamente teológico-, pero intentando poner las bases para una posterior comprensión más global de su obra.

\section{3. ¿QUÉ ENTIENDO POR SUSTRATO FILOSÓFICO?}

Aclaremos desde el principio que se comete, en cierto modo, un anacronismo al tratar de indagar el sustrato filosófico de Eustacio de Antioquía. En la mentalidad de los cristianos de aquella época, a comienzos del s. IV, aún no existía la posibilidad de elaborar un pensamiento cristiano que no fuese idéntico a la verdadera filosofía. El cristianismo era la filosofía verdadera. Vistas así las cosas, hablar del sustrato filosófico de Eustacio de Antioquía sería tanto como hablar de todo su pensamiento. Pero no es este el objetivo. Como ustedes lo habrán advertido desde el comienzo sin duda, trato de identificar qué corrientes filosóficas paganas han influido más de cerca en la "teología" de Eustacio de Antioquía.

Es igualmente anacrónico hablar de sustrato filosófico en Eustacio porque, también desde la mentalidad de los antiguos cristianos, cualquier cosa que de bueno hubieran dicho los paganos y pudiera pasar a cristianos como sustrato era, en realidad, en manos de ellos, un hurto más de los llamados furta graecorum. En la misma sede antioquena se había pronunciado de esta manera uno de los predecesores de Eustacio a propósito de los filósofos:

Habiendo sido predichos estos tormentos por los profetas, los poetas y filósofos que vinieron después robaron esto de las escrituras santas con el fin de otorgarle autoridad a sus doctrinas (7).

Difícilmente, pues, entendería un cristiano recibir como préstamo para cimentar su pensamiento algo que ya antes era reconocido como un "hurto". Antes bien, era propio también de los cristianos una cierta superioridad con respecto a los paganos, fundada en la mayor dignidad y fiabilidad del depósito de fe transmitido por la Iglesia apoyada en las Escrituras, en comparación con los mitos o explicaciones paganas. El mismo Teófilo se expresa en otro lugar:

Ahora quiero demostrarte con más precisión, Dios mediante, lo referente a los tiempos, para que reconozcas que nuestra palabra no es reciente ni mítica, sino más antigua y más verdadera que la de todos los poetas y escritores, que escribieron sobre lo incierto. Pues algunos diciendo que el mundo es ingénito terminaron en lo infinito, otros, diciendo que era producido, dijeron que tiene ya quince miríadas tres mil setenta y cinco años. Esto lo narra pues Apolonio

(7) Teófilo de Antioquía, A Autólico 1, 14, 2, int. texto gr. tr. y ns. de J. P. Martín [FuP 16], Madrid 2004, p. 91. En nota J. P. Martín hace referencia al origen judío de este topos de los furta graecorum, utilizado abundantemente también por los cristianos. 
el egipcio. Y Platón, que se cree ha sido el más sabio de los griegos, ¡a cuántas tonterías fue a terminar! Porque en las Repúblicas escritas por él se encuentra que dice literalmente... (8)

Ahora bien, se trata de un anacronismo legítimo, porque nos permite comprender hoy a nosotros mucho mejor los avatares de la historia del dogma cristiano, que no pueden llegar a entenderse al margen del estudio de la filosofía pagana y de su propia evolución. Con todo, conviene recordar este preámbulo para evitar la tentación de perseguir la búsqueda de un sistema filosófico tal cual en un autor cristiano. Los cristianos, efectivamente, hicieron gala de una gran libertad para coger de la filosofía pagana aquello que más utilidad les proporcionaba y dejar lo que les resultaba imposible integrar dentro del dogma cristiano o, sencillamente, les era inútil para la persecución de su objetivo. Ahora bien, la pregunta sigue en el aire, ¿se puede identificar, entre todas las sectas filósoficas imperiales, alguna corriente de la que Eustacio registre, conscientemente o no, una mayor influencia?

\section{LA LEJANÍA AFECTIVA DE EUSTACIO CON RESPECTO A LA TRADI- CIÓN PLATÓNICA}

Eustacio se nos muestra como un autor poco proclive a la recepción de dogmas neoplatónicos. Eustacio conoce y cita a Platón. No parece interesado en polemizar directamente contra él, sino, más bien, contra aquellos que, dentro de la Iglesia, se sirven de planteamientos platónicos. Se sabe bien que Eustacio fue uno de los grandes adversarios del pensamiento de Orígenes y, por cierto, cabe recordarlo como uno de los más preparados de su tiempo.

En el fr. 31, Eustacio polemiza ciertamente contra la transmigración de las almas del siguiente modo:

Pero dado que claramente se reconocen ellos mismos ahí cogidos, cambiando de opinión, se inventan el agua del olvido, la cual -dicen- al beber cada uno de ellos les hizo olvidar las generaciones de sus vidas naturales. Pero que estas cosas son legendarias y tienen muy poco de filosofía, ninguno de los que están dotados de buen entendimiento lo ignorará. En efecto, ¿qué diremos a los Pitágoras y Platones? ¿Vosotros mismos, tomando del agua del olvido, bebisteis o, por el contrario, olvidasteis beberla? Pero entonces, si vosotros habéis sido capaces de evitar la bebida del olvido, está claro que también otros muchos. Pero si habiendo respirado el aire común a todos (cf. Sab 7, 3), bebisteis a placer el agua del olvido, ¿cómo y de dónde fabricáis los mitos, asumiendo que las almas de los hombres se transforman en asnos y en lobos y en animales de todo tipo? ¿De dónde conocéis el género de estas corrientes de agua? En efecto, [es imposible] ya sea porque no hayáis tenido experiencia de ellas y desconocéis el efecto de su asimilación, ya porque hicisteis desaparecer con el olvido el recuerdo de su uso, habiendo tirado fuera el conocimiento. Y por

(8) Teófilo de Antioquía, A Autólico 3, 16, 2-3, pp. 239. 241. 
haberse vuelto hacia estas cosas de superstición pagana, se equivocaron; por haberse servido de los pensamientos egipcios (9).

La doctrina de la transmigración de las almas estaba ampliamente difundida en determinados ámbitos paganos (pitagóricos, platónicos) y de esoterismo popular. Incluso compartida por algunos cristianos y judíos. Orígenes mismo debatió en torno a ella para rechazarla; ahora bien, el peculiar modo con que Orígenes alegorizaba la vida del hombre dio pie a que su pensamiento fuera tachado de favorable a la metensomatosis o transmigración de las almas. El hecho de que Pánfilo de Cesarea, autor contemporáneo a Eustacio, tuviera que defender la memoria de Orígenes de esta falsa acusación, muestra hasta qué punto tenía en el flanco de mira una vez más Eustacio a los partidarios de Orígenes (10).

Más de cerca tiene a toda la tradición origeniana defensora de la preexistencia de las almas y de la inmortalidad del alma por naturaleza. Leamos el fr. 52:

Platón en el Fedón, dice que Sócrates sostenía: 'Toda alma es inengendrada;

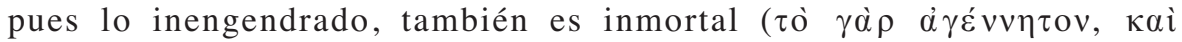

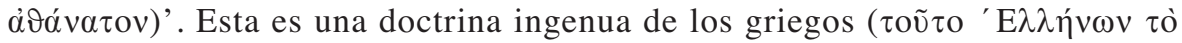

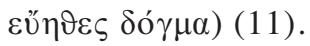

La cita, en realidad, se ajusta más al diálogo Fedro 245c5-246a, 2, como lo sugiere el reciente editor. En estas breves líneas, Eustacio se aleja sensiblemente, no solo del neoplatonismo reinante en su época, sino también de muchos de los cristianos, y no solo arrianos, de raigambre alejandrina.

Sorprendamos ahora, de un modo un poco más indirecto, la lejanía de Eustacio con determinados postulados neoplatónicos. Entramos en el disputado campo de las pasiones del alma. Se sabe que uno de los logros de Porfirio fue precisamente hacer de toda el alma, y no solo del nous, algo inaccesible en primer grado a la afección. Su afán en dotar de trascendencia al alma entera le llevó a dejar más claro que las pasiones repercutían y afectaban en primer lugar al instrumento humano, al cuerpo.

En un campo con otros intereses, Eustacio plantea batalla a los arrianos afirmando machaconamente una y otra vez que Cristo asumió un alma humana. Que no se limitó a asumir tan solo un cuerpo, desprovisto de alma, donde las funciones de esta las llevaría a cabo el Logos. Como se sabe, estaba en juego toda la doctrina trinitaria y cristológica. De admitir que el Logos acarreaba con las funciones del alma, se seguía el carácter, en cierto modo, alterable del Logos encarnado, sometido a la tristeza, al cansancio, etcétera. Eustacio planta cara a los arrianos apoyado sólidamente en varios pasajes de la Escritura. Uno le era particularmente favorable.

(9) Fr. 31, p. 101; cf. también frs. 30, 54, pp. 99-100, 125-126.

(10) El framento 31 no da para más. Lo sorprendemos como casi todos ex abrupto, pero no nos debe hacer pensar que Eustacio afrontara su polémica contra los filósofos paganos directamente. Da la impresión de que a Eustacio lo pagano le interesó siempre en función de la polémica interna eclesial. Por lo demás, acerca de la transmigración de las almas en Orígenes, cf. la voz de M. Maritano, Metensomatosi, en Origene. Dizionario, a cargo de A. Monaci Castagno, Roma 2000, pp. 274-276, con bibliografía.

(11) Eustathii opera omnia, p. 125. 


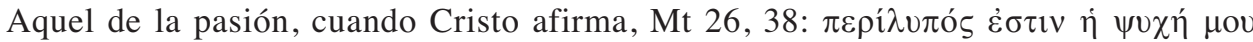

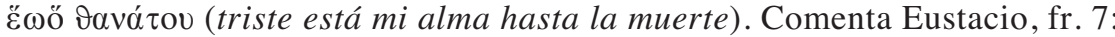

Que [Jesús] no dijo: 'Triste está mi cuerpo', no fuera a ser que alguno entendiese que, supuesto que el espíritu [de Cristo] permanecía en su idéntica condición, el templo mismo de su cuerpo (cf. Jn 2, 21) se entristecía, sino dice 'triste está mi alma'. Y, efectivamente, la pasión ( $\tau$ ò $\pi \alpha ́ \vartheta o \varsigma)$ sobrevenida [de la tristeza] repercute primordialmente en el alma $(\tau \tilde{\eta} \psi \nu \chi \tilde{\eta}$

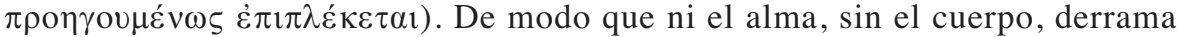
lágrimas, ni el cuerpo sin el alma queda abandonado al llanto, sino que lo que procede de ambos tiene una mezcla proporcional. En efecto, el alma, que queda afectada en su conjunto por la tristeza o la alegría que incurren en ella, sirviéndose del golpe ardiente, calienta el humor líquido, y calentado, se desborda por medio de los ojos, en parte evaporándose lo que corre, y en parte segregando un flujo más espeso. Luego que estas son pasiones del alma y del cuerpo, ninguno lo pondrá en duda. No conviene referir estas cosas al espíritu divino, en cuanto que lo divino se encuentra siempre en las antípodas de cualquier mal (12).

En nada se arredra Eustacio a la hora de aplicar la pasión de la tristeza primordialmente al alma. Porque ahí radica el punto fuerte: en el adverbio $\pi \rho 0-$ $\eta \gamma o u \mu \varepsilon ́ v \omega \varsigma$. Un cristiano, o un filósofo de inspiración neoplatónica, estaría dispuesto a admitir una cierta afección del Logos (el alma o nous u hombre interior plotiniano, respectivamente), pero dicha afección en ningún caso repercutiría en Él de modo primario, sino siempre secundario, mientras que la pasión en su primer grado se aplicaría al cuerpo humano. De hecho, en la misma ciudad de Antioquía, no hacía mucho tiempo que un cristiano, de clara formación alejandrina, contemporáneo al tiempo de Porfirio, había afirmado en polémica contra un antioqueno:

Y ni estaba privado de las pasiones principalmente humanas (oủ $\tau \varepsilon \delta \dot{\varepsilon}$

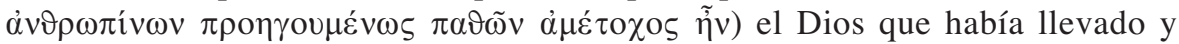
vestido lo humano, ni era inseparable de las obras principalmente divinas lo humano, en el cual estaba y por medio del cual hizo estas. Fue plasmado

(12) Eustathii opera omnia, p. 68. Del mismo tenor resulta el fr. 6, ibid. p. 67: "Que digan los adversarios si el Logos mismo de Dios, que es Dios, es impasible o es contenido dentro de las

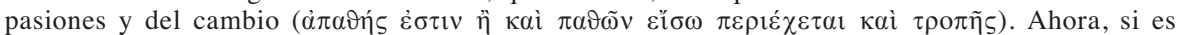
susceptible de pasión, se anatematizan ellos mismos, que afirmaron por escrito de él que era inalterable ( $\left.\dot{\alpha} v \alpha \lambda \lambda \operatorname{oí}_{\omega \tau \tau} \mathrm{v}\right)$, habiéndolo confesado por escrito, en privado y en público, en el

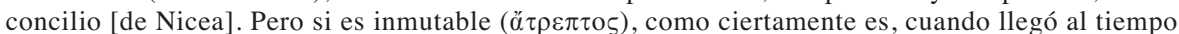
de su muerte corpórea, ¿qué era lo que sufría?, ¿quién era el que decía: 'Triste está mi alma hasta la muerte' (Mt 26, 38)? La tristeza y las lágrimas, la risa, el sueño, el hambre, la sed, el deseo, el

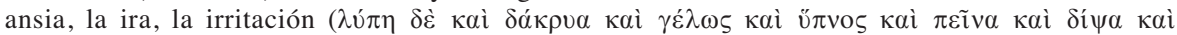

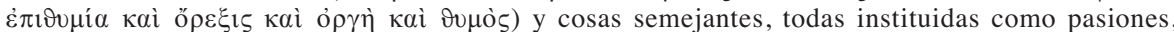
dejan ver cambios al pie de la letra. Entonces, si el Logos divino es inalterable, ¿qué es lo que experimentaba el cambio y estaba sometido a las pasiones de la tristeza? ¿Acaso el alma?", y muchos otros fragmentos. 
principalmente como hombre en el vientre, y secundariamente era Dios en el vientre el que estaba unido sustancialmente con lo humano (13).

Se trata de Malquión, el célebre opositor de Pablo de Samosata, obispo antioqueno. El término $\pi \rho \gamma_{\gamma}$ encuentra muy extendido en época imperial y no se ciñe a ninguna secta filosófica en concreto. Ha de entenderse como principalmente, sustancialmente en oposición a secundariamente, accidentalmente, por azar, por participación. Volviendo a nuestro fragmento, a Eustacio le interesa salvar lo inmaculado e inalterable del Logos y del Espíritu divino que habitaba en Jesucristo, y atribuir por entero sustancialmente la pasión de la tristeza al alma humana que el Logos asumió al revestirse del hombre (por emplear términos eustacianos). Los arrianos, por el contrario, no tenían inconveniente en atribuir parte de la pasión al Logos, desprovisto de alma, pero unido a un cuerpo humano que había sufrido principalmente la pasión de la tristeza. Este Logos no sufría como sufre el alma de Cristo en Eustacio. Sufriría tan solo secundariamente, por accidente, por estar unido al cuerpo, como había dicho ya Malquión, envuelto quizás en otros intereses, pero abriendo camino a la cristología arriana (y, más tarde, apolinarista). Ahora bien, de esta concepción cristológica arriana se desprendía un Logos alterable, si bien, en segundo plano. Un Logos mutable, un Logos que ya no era aquel Logos verdaderamente Dios, nacido del Padre mismo, inmutable como el mismo Padre, sino un Logos creado excelentemente por el Padre, y, por ello, sujeto a cierta mutación en su contacto con el cuerpo humano (14).

A favor de los arrianos se levantaba la antropología neoplatónica, ocupada en trascender el alma u hombre interior unido y afectado por su unión con el cuerpo humano u hombre exterior, que era el verdadero sujeto de las pasiones. Muy lejos de esta explicación, encontramos estas líneas de Eustacio donde el antioqueno centra la pasión, otorgando al alma y al cuerpo su parte proporcional en ella. Más aún, distinguiendo que determinadas pasiones como la tristeza, tocan directamente al alma, aunque no se puedan manifestar ni efectuar sin la concurrencia del cuerpo.

\section{LA INCOMPATIBILIDAD DEL SISTEMA EUSTACIANO CON ALGUNOS PRINCIPIOS ESTOICOS FUNDAMENTALES}

Está muy extendida la idea de que, frente al gran número de cristianos que denuncian un fuerte influjo de ideas platonizantes, se yergue un grupo, tal vez no tan nutrido, que presenta tendencias más cercanas al estoicismo. Esto, sobre todo, resulta cierto -se dice- para algunos Padres de la Iglesia como Ireneo, Tertuliano, que algunos sitúan en la llamada tradición asiática. Aunque hay algo de cierto en esto,

(13) Fr. 34 de Malquión, cf. texto en P. de Navascués, Pablo de Samosata y sus adversarios, Roma 2004, pp. 83. 115. Comentario acerca de este fragmento en pp. 409-411.

(14) A decir de Eustacio, fr. 19, Eustathii opera omnia, pp. 80-81, la causa de la herejía arriana (de sostener un Logos creado, no engendrado) era precisamente su peculiar cristología, en la que el Logos experimentaba mutaciones incompatibles con la naturaleza divina propia de un Hijo engendrado por el Padre, pues no es posible que lo mutable sea engendrado por una naturaleza

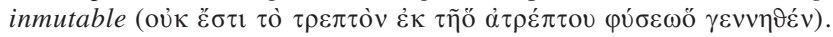


yo tiendo a pensar que Ireneo deja bastante patente la libertad con que usa de conceptos y categorías filosóficas, sin llegar a comprometer lo más fino de la tradición que él recibe en el seno de la Iglesia. Este no sería el caso, en cambio, del siempre difícil de clasificar Tertuliano. En algún momento tiene afirmaciones típicas de un estoico, como la conocida afirmación -que reposa sobre la afirmación de Jn 4, 24: Dios es espíritu- en su tratado Adversus Praxean 7, 8: "Quis enim negabit Deum corpus esse, etsi Deus spiritus est?" (15). Si bien en la obra de Tertuliano la afirmación juega un papel antimonarquiano, para dar el mayor grado de personalidad y consistencia al Verbo, en absoluto, repugna emparentar esta afirmación de Tertuliano con el dogma estoico de que todo lo que existe es cuerpo. Dicha afirmación, en sentido negativo, queda plasmada perfectamente por Sexto Empírico cuando sostenía en Adv. math. 8, 263:

Lo incorpóreo, según ellos [los estoicos] no puede por naturaleza ni actuar ni

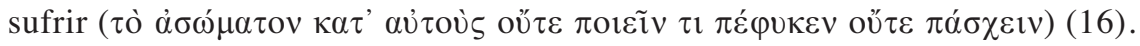

Ahora bien, en Eustacio advertimos las siguientes afirmaciones:

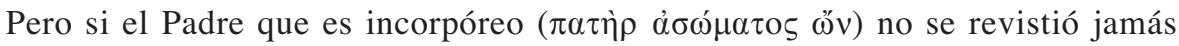

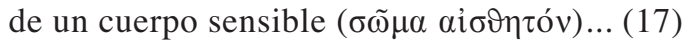

Y esta, a propósito de los antropomorfismos de la Escritura:

Porque cuando el Dios, que lo gobierna todo, hablaba como si tuviera alma,

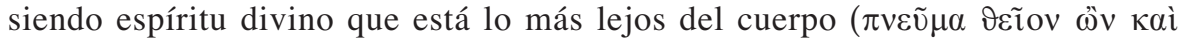

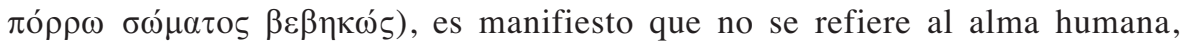

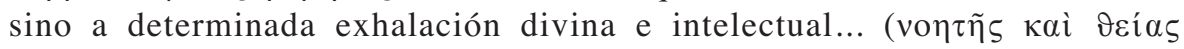

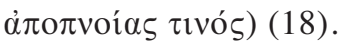

En un silogismo ad absurdum, donde trata de demostrar que el hombre psíquico y el hombre espiritual a los que se refiere san Pablo en 1 Cor 15, 45 ss. están siempre, en cualquier caso, compuestos de cuerpo y alma y, de este modo, una vez más poder rebatir la tesis arriana, conforme a la cual Cristo no asumió un alma, podemos sorprender a Eustacio con estas palabras:

En efecto, si fuera él, en sí mismo, espiritual, está claro que sería también

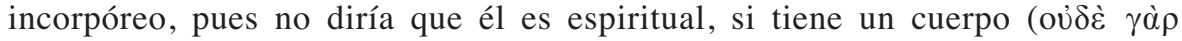

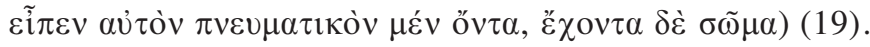

(15) Q.S.F. Tertulliano. Contro Prassea, ed. G. Scarpat [Corona Patrum 12], Torino 1985, p. 158.

(16) SVF II 363, p. 123.

(17) Fr. 2, p. 65.

(18) Fr. 3, p. 65.

(19) Fr. 44, p. 117. 
En otro lugar se refiere claramente al espíritu incorpóreo de la sabiduría (el Espíritu Santo), el cual no puede ser conforme a los hombres corpóreos (20), o describe los cuerpos como visibles y comprensibles por la percepción sensible (21).

Por consiguiente, difícilmente se adscribirá a Eustacio en un marco de referencia estoico, cuando falta este primer pilar de la corporeidad de todo lo existente. Y no solo. Advertimos igualmente un concepto de la divinidad que está muy lejos de ser inmanente. Lo divino queda siempre por encima de lo humano, a un nivel inalcanzable por naturaleza, trascendido, puramente al margen del mundo del hombre. Se aprecia la tendencia en Eustacio a establecer dos niveles: el intelectual y divino e incorpóreo y el sensible, humano y corpóreo, que nos alejan también bastante del ámbito de reflexión estoico (22).

Por último, trayendo a la memoria los pasajes antes citados, a propósito de la controversia de Eustacio contra los arrianos en torno a la pasión de la tristeza del alma de Cristo, concluiremos que con dificultad se puede atribuir a principios estoicos las respuestas pertinaces del antioqueno, donde se subraya cómo propio del alma humana, a diferencia del espíritu divino, es la pasión. Pasión que, por otro lado, es incapaz de experimentar sin el cuerpo. Pasión que se atribuye proporcionalmente al cuerpo y al alma. Divisamos, pues, en esta otra temática de las pasiones una considerable distancia entre Eustacio y las pasiones, tal cual fueron consideradas por los estoicos, como juicios contra natura del alma, como juicios irracionales debidos a movimientos excesivos que desbordan la disposición moral del hombre (23). La pasión es, en cierto modo, para los estoicos, un error, una falta. ¿Cómo se podrían sostener, entonces, al mismo tiempo, por parte de un cristiano como Eustacio, las repetidas series de las pasiones sufridas por Cristo?

Si este ha sido nuestro resultado, debemos confesar honradamente que no coincide con lo que, en algún momento, se ha dicho de nuestro obispo antioqueno, al que se le ha adscrito a la tradición asiática, tocada por el materialismo estoico (24). El hecho de que Eustacio comparta con autores como Hipólito o Tertuliano un distanciamiento afectivo notorio con la línea alejandrina no basta para incluirle entre los Padres, tocados de modo especial por la tradición del Pórtico.

(20) Cf. fr. 58, pp. 139-140; también en el fr. 78, p. 148, se alude a la Sabiduría (Espíritu Santo) incorpórea.

(21) Cf. fr. 78, p. 148 .

(22) Valga como ejemplo el fr. 82, pp. 152-153, donde el que recibe la gloria no es el Padre perfecto, infinito, incomprensible, ni tampoco Su Logos, Dios engendrado de Dios mismo e instrumento activo de toda la creación, sino el hombre de Cristo. O a propósito de la unción, el fr. 85, p. 154, donde el que unge es el que es Dios por naturaleza, y el ungido es el que lo será por virtud merecida.

(23) Cf. SVF III, pp. 92 ss.

(24) Cf. M. Simonetti, Studi sulla cristologia del II e III secolo, Roma 1993, p. 327, n. 144. Algún fragmento donde se habla que el Hijo de Dios, imagen de Dios, es fuego por naturaleza (oṽ $\sigma \alpha \tau \tilde{\eta}$

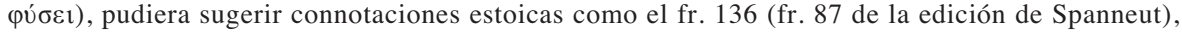
pero, por un lado, en la última edición este fragmento se sitúa entre los fragmenta dubia et spuria y, por otro, tampoco se impone exclusivamente esta explicación. Bien pudiera derivar la imagen del fuego de la misma Escritura, donde ligada a la manifestación de Dios aparece numerosísimas veces o, tal vez, de líneas filosóficas de impronta aristotélica y "contaminación" estoica, como aclaro más adelante. 


\section{EUSTACIO Y LOS ADVERSARIOS ANÓNIMOS PERIPATÉTICOS DE ALEJANDRO DE AFRODISIA}

No pretendo someter a Eustacio a una rueda exhaustiva, ni estoy preparado para ello. Prescindo de la confrontación con el epicureísmo, dada la marginal contribución de esta secta en comparación con otras al pensamiento cristiano (25). Digo marginal, y, con ello, quiero dar a entender que hubo su parte, tal como se ha recordado más de una vez.

En cambio, sí que resulta interesante la comparación con el aristotelismo. Según una opinión bastante difundida, el aristotelismo -como el epicureísmo- tampoco logró gran aceptación entre los cristianos (26), y, más aún, se adjudicó cierto estilo de argumentación peripatética a los herejes (27). Sin embargo, ni es del todo cierto para los mismos Padres, los cuales, más de una vez, ponderan el beneficio de la ciencia aristotélica y citan a alguno de sus valedores (28), ni lo es desde una sana perspectiva histórica, como enseguida mostraré.

Se suele aludir para subrayar la incompatibilidad del aristotelismo con la fe cristiana de los Padres a algunos de sus dogmas principales como la mortalidad del alma, la negación de la providencia divina, la eternidad del universo, etcétera. Más de una equivocación se comete. En primer lugar, no todo es igual de inadmisible para un cristiano. La inmortalidad del alma per se no era un axioma universal dentro de la Iglesia; para algunos autores, como Justino, el alma es inmortal porque Dios quiere, y lo es, en beneficio del futuro cuerpo resucitado (29). Tan lejos, pues, de Justino encontramos a Aristóteles como a Platón en lo que respecta a la escatología psíquica. Por lo demás, no se tiene en cuenta en este caso, lo que sí se considera para el caso del neoplatonismo, o sea, el hecho de que los Padres no recibieron nunca, en general, una corriente filosófica sin más, sino que, más bien, se inspiraron como fuente en las Escrituras leídas y transmitidas oralmente por la tradición de la Iglesia y, consciente o inconscientemente, recurrieron a préstamos de la filosofía que pudieran servir para mantener sano, vivo y eficaz el anuncio de la fe cristiana. Así las cosas nada obsta para que, al menos, a modo de hipótesis, pudieran acudir también a la secta peripatética.

Pero, además, se añade el dato de que tampoco las corrientes filosóficas se presentaban uniformes en absoluto. Esto es verdadero también para el caso del aristotelismo imperial que cobró un impulso muy particular con la obra del Comentador, por excelencia, es decir, de Alejandro de Afrodisia, s. II d. C. Con él se da un

(25) Cf. J. Antolín Sánchez, El epicureísmo en el cristianismo primitivo, Valladolid 2003.

(26) Cf. la voz de S. Lilla, Aristotelismo, en Diccionario Patrístico y de la Antigüedad Cristiana, ed. A. di Berardino, vol. I, Salamanca 1991,pp. 203-211.

(27) Cf. el anónimo antiartemonita citado por Eusebio de Cesarea, Historia Eclesiástica 5, 28, 13-14, ed. A. Velasco-Delgado [BAC 349], vol. I, Madrid 1997², pp. 343-344.

(28) Véase el caso de Anatolio, varón eclesiástico alejandrino activo en el último tercio del s. III, al frente de la escuela peripatética de la ciudad, recordado por Eusebio de Cesarea, Historia Eclesiástica 7, 32, 6, ed. A. Velasco-Delgado [BAC 350], vol. II, Madrid 1997², p. 498; o el caso de Cirilo de Alejandría, que conoce y utiliza el De fato de Alejandro de Afrodisia, cf. Alessandro di Afrodisia. La provvidenza. Questioni sulla provvidenza, ed. S. Fazzo, Milano 1999, p. 69.

(29) Cf. San Justino, Diálogo con Trifón 4-7, en Padres Apologistas Griegos, ed. D. Ruiz Bueno [BAC 116], Madrid 1954, pp. 307-314. 
tono trascendente a la reflexión del Liceo, se incorpora la providencia al sistema y se sigue abriendo paso con su propia autonomía la reflexión aristotélica, frente a platónicos y a estoicos, de modo particular. No obstante, sí que es cierto que tal empresa terminará sucumbiendo casi por entero, una vez que el neoplatonismo triunfante de mediados del s. III terminara aglutinando los postulados aristotélicos dentro de su propia ontología (30). Casi por entero, porque en el s. IV todavía adivinamos la presencia de comentadores aristotélicos no platónicos, como es el caso de Temistio.

El fenómeno no se ha dejado pasar y, aunque con poca resonancia en los manuales al uso, más de una vez se ha señalado la afinidad que, a diferencia de casi todo el resto del Oriente cristiano, se estableció en Antioquía y sus alrededores entre el pensamiento cristiano y determinadas categorías aristotélicas. Parece que la obra de comentadores paganos como Temistio, influyentes en la zona de Siria y Asia Menor, no sería del todo ajeno a ello. El dato se ha puesto de relieve para los casos de Diodoro de Tarso, Nestorio, Julián de Eclana y otros autores de los ss. IV y V (31). Yo creo que no hay inconveniente para ensanchar la franja cronológica del influjo particular del aristotelismo sobre el cristianismo afincado en Antioquía, haciéndolo comenzar desde la segunda mitad del s. III (32).

Si se confirma también para Eustacio, su caso entonces se nos revela bastante decisivo, porque se convertiría en el único anillo que testimonia para nosotros la permanencia en cadena del influjo antioqueno, con sus respectivas modificaciones, entre Pablo de Samosata y el período postniceno. Volviendo, pues, a este autor, señalemos que, en más de una ocasión, encontramos entre los fragmentos de Eustacio que los fenómenos humanos quedan definidos por lo psíquico y lo corpóreo. Si se trata de las pasiones, si se trata de la misma definición del hombre, tanto el alma como el cuerpo tienen su parte proporcional.

El hecho de encontrar este binomio de alma y cuerpo dice en sí poco. Lo crucial es ver que para Eustacio, el alma incorpórea unida al cuerpo son la base del hombre perfecto, cuya perfección viene dictada por la forma superior del Espíritu. Bautizando este módulo aristotélico, habría que decir que cuando el cuerpo realiza las obras, dinamizado por la forma superior del Espíritu, gracias también a la virtud del alma, se muestra la perfección del hombre. Vayamos otra vez al fr. 44:

Porque decimos que es [hombre] psíquico el compuesto de alma y cuerpo, y [hombre] espiritual, el que ha sido concebido a partir del Espíritu Santo. En efecto, si no hubiera tenido un alma, tampoco habría obrado las junturas del cuerpo, dado que denominándole, ante todo, espiritual, no se haría mención ni del alma ni del cuerpo. Pues si fuera él, en sí mismo, espiritual, está claro

(30) Cf. P. Donini, Tre studi sull'aristotelismo nel II secolo d. C. [Historia politica philosophica 7], Torino 1974; id., Le scuole, l'anima, l'impero: la filosofia antica da Antioco a Plotino, Torino 1982.

(31) Cf. E. Ivanka, Hellenisches und Christliches im Frühbyzantinischen Geistesleben, Wien 1948; A. Thuillier, La tradition aristotélicienne à Byzance des origines au VIIe siècle. La formation de la scolastique byzantine, en Association Guillaume Budé. Congrès de Lyon 8-13 Septembre 1958. Actes du Congrès, Paris 1960, pp. 186-197; N. Cipriani, Echi antiapollinaristici e aristotelismo nella polemica di Giuliano, en Augustinianum 21 (1981), pp. 373-389.

(32) Cf. P. de Navascués, Pablo de Samosata y sus adversarios, Roma 2004, pp. 273-281. 
que sería también incorpóreo, pues no diría que él es espiritual, si tuviera un cuerpo. Pero si es hombre, está claro que nació hombre, por la mezcla del cuerpo y del alma, mostrando con esto que el hombre perfecto ( $\tau \dot{\lambda} \lambda \varepsilon 10 \varsigma$ ) solo es el que procede de todos, el que tiene que tener proporcionalmente todas las virtudes (33).

Si atendemos ahora a este nuevo fr. 22:

Porque si el Logos condujo al hombre de Cristo, tras haberlo compuesto con las armonías del Espíritu, a fin de que, por medio del origen común librara de la corrupción inicua a las almas congénitas junto con los cuerpos ( $\tau \alpha \grave{s}$

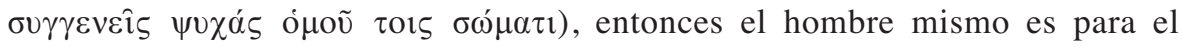
resto de hombres creyentes causa de salvación, como Pablo dice en la carta a los Romanos (Rom 5, 15)... (34)

Eustacio excluye cualquier preeminencia cronológica del alma con respecto al cuerpo, lo cual se encamina hacia la misma conclusión, es decir, a retener al alma como forma del cuerpo, que deja de existir sin la materia y que vuelve a existir con la materia, pero nunca al margen del cuerpo (o materia). Decisivo y concluyente al respecto me parece un largo párrafo donde aparece literalmente el alma como forma del cuerpo:

Pues, por su falta de entendimiento, los arrianos dicen que es imposible que se introduzcan las mociones de dos espíritus en la única condición corpórea. A partir de las obras mismas y de las palabras queda mostrado que Cristo tenía un alma que se sometía a los cambios propios del hombre, y era portador de un espíritu divino que permanecía enteramente inmutable, dado que también el espíritu, con el resto de hombres del modo acostumbrado, entraba en ellos para edificarles cual templo, tal como se dice que Esteban estaba lleno del Espíritu Santo o igualmente Bernabé (cf. Hech 6, 5; 7, 55; 11, 24). Y también el Señor dijo: El que me ame guardará mi palabra, y vendremos a él yo y mi Padre, y haremos morada en él (cf. Jn 14, 23). Pero si, por una parte, no rechaza al alma para cohabitar con ella, ni, por otra, debido a la introducción de lo mejor no renuncia a lo peor, sino que, mucho antes, lo renueva en la virtud cambiándolo por el trato con lo divino, y el Padre junto con el Hijo están deseando por su propia voluntad habitar en él, está claro que se puede admitir que la forma del alma y el espíritu divino convivan en un mismo sujeto ( $\pi \rho \delta_{\delta} \eta \lambda$ ov ö $\tau 1$

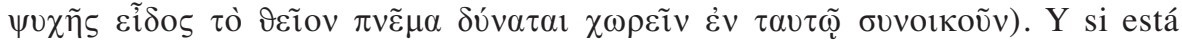
garantizado que [el espíritu divino] habita en el resto de los hombres, alegrándose de convivir con las almas que viven del modo más piadoso, no obstante el hecho de que no sean absolutamente impuras -en efecto, el nous, en cualquier caso, está en común con una mezcla de impureza, por pequeña que sea- el alma de Cristo impura, sin culpa, sin mancha, que, en absoluto, tiene la más

(33) Fr. 44, pp. 117-118.

(34) Fr. 22, p. 85. 
mínima huella del pecado, ¿no convivirá con mucha más razón con el espíritu divino, a causa de la excelencia de su pureza y su justicia? En efecto, el resto de hombres santos, que vienen a la luz a raíz de las mezclas corpóreas y se muestran como templos humildes, fructificaron en el buen olor del Espíritu por participación, mientras que Cristo, hecho cuerpo por el Espíritu santo, como Unigénito, sacó a la luz la naturaleza de lo mejor, no por participación, sino que completamente habitó en él mismo la plenitud de la divinidad ( $\mathrm{Col} 2,9)$, como dice el apóstol. Pero si es plenitud de la divinidad el Hijo de Dios, entonces es perfecto; y si es perfecto, está claro que ha sido engendrado del Padre perfectísimo. Y el que ha sido hecho perfecto gracias a la máxima virtud de la divinidad, no se dispondría para sí mismo un templo imperfecto y capitidisminuido de su parte mejor, sino que presentó en sí mismo al hombre completamente sano; no le sanó parcialmente y descuidó sin cura lo más digno de él, sino que administrando la cura de todo el hombre, asumió todo lo nuestro $(35)$.

La inspiración de base peripatética, a mi juicio, permite a Eustacio discurrir en este caso con un esquema sólido. La perfección del hombre queda reflejada solo en el hombre asumido y sanado por Cristo. Un hombre de Cristo sin alma, como querrían los arrianos, es incomprensible para Eustacio, pues ¿qué sería la materia amorfa? Y si la forma del cuerpo de Cristo la proporciona el Logos, sin colabora-

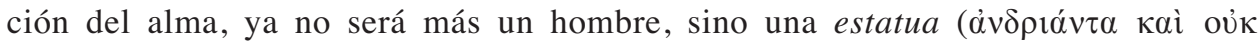

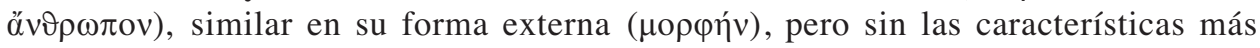

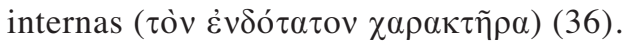

El alma del hombre mutable queda catalogada como peor en comparación con el espíritu divino inmutable; pero como lo mejor, en relación con el cuerpo del que es forma y con el que existe inseparablemente. Ahora bien, ambos espíritus (el alma y el espíritu divino) pueden convivir para aportar al compuesto el necesario perfeccionamiento. Cada hombre, en virtud de la participación ( $\mu \varepsilon \tau o v \sigma i ́ \alpha)$ del Espíritu, llega a su perfección; el hombre de Cristo, de modo eminente, por residir en él, no una parte, sino la plenitud de la divinidad (que de este y otros fragmentos podemos deducir que es el Logos). Al final asoma en las últimas líneas de Eustacio un principio clásico de la teología que el Nacianceno habría de formular con dos pala-

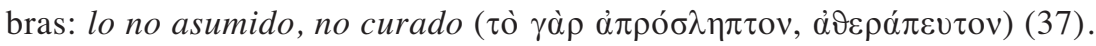

Es una cristología que evita con agilidad los excesos del cristianismo de inspiración neoplatónica donde lo sensible, lo corpóreo reciben una atención secundaria, en el mejor de los casos. La unidad de funcionamiento de la antropología eustaciana se deja ver a menudo en los fragmentos donde rebate el modo de concebir las pasiones de Cristo. Son pasiones comunes al cuerpo y al alma, como tuvimos ocasión de ver más arriba. En unas breves líneas, el propio Eustacio nos ofrece una definición de alma, fr. 51:

(35) Fr. 50, pp. 121-122.

(36) Cf. fr. 4, p. 66.

(37) Epístola 101, 32, en Grégoire de Nazianze. Lettres théologiques, ed. P. Gallay [SC 208], Paris 1974. 
Y es conveniente que en breve denunciemos qué es en una palabra el alma. Que es un espíritu invisible, es patente para todos. Ahora, el movimiento la retrata a ella misma a partir de los órganos de la percepción sensible, y, al dar forma a los actos, proporciona para todas las cosas representaciones visibles

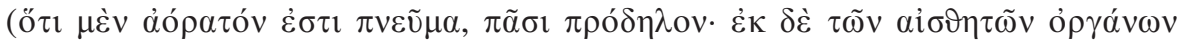

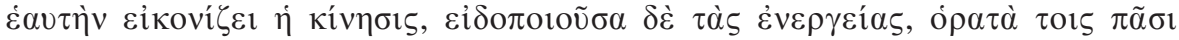

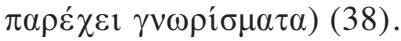

Pocas líneas que encierran más de una clave. En primer lugar, destaquemos que en la definición no juega ningún papel la fe de Eustacio y que, a priori, podría pertenecer a cualquier pagano instruido en alguna de las escuelas imperiales.

Se aprecia una tensión entre lo invisible del alma y lo visible del cuerpo que queda resuelto en virtud de los órganos sensibles del cuerpo que se mueve conformado por el alma. Hay un interés en unir al alma con el movimiento del cuerpo sin declararla a ella, por eso mismo, móvil. Hay un interés en colocarla como causa de los actos y actividades humanas sin identificarlo con ella. Es solo a través del cuerpo conformado por el alma como el alma se da a conocer visiblemente. Y todo esto son líneas de fuerza que encontramos, por ejemplo, en el De anima 22-24 de Alejandro de Afrodisia (39).

En fin, a lo largo de todo el pensamiento eustaciano asoma una debilidad que, según mi entender, delata aún más la proveniencia aristotélica de su entramado. Se trata de una falla insalvable entre lo divino y lo humano, entre el Logos y el hombre asumido por el Logos. En multitud de ocasiones, Eustacio señala la franja divisoria entre el mundo impasible, intelectual, incorpóreo, invisible, incomprensible y divino y el mundo pasible, sensible, corpóreo, visible, comprensible y humano. Y de este pie cojeará siempre en las futuras controversias cristológicas de los ss. V y VI la cristología de cuño antioqueno. Si su punto fuerte consiste, ciertamente, en la salvaguarda de la íntegra humanidad de Jesucristo, es menester confesar también este flanco débil que ofrecía a la crítica de los alejandrinos. Como muestra, fr. 128:

Por eso Cristo decía: Yo soy el camino, la verdad y la vida. Entonces, mostrando con el nombre de el camino, el vestido del hombre, que es lo propio de lo corpóreo y visible -en efecto el camino es una cierta porción de tierra que queda constituido como suelo sensible-, pero con los nombres de la verdad y la vida, mostrando la naturaleza del Padre. La verdad, efectivamente, es una realidad inteligible, que no cae bajo el tacto ni la vista (40).

Muchos otros lugares de la obra que nos ha llegado por entero, su interpretación de la evocación del espíritu de Samuel por parte de la pitonisa en 1 Re 28, nos reafirman en la coherencia de Eustacio, para el cual solo se puede hablar de hombre compuesto de alma y cuerpo:

(38) Fr. 51,p. 123. Alguna fuente presenta estas líneas que encabezan el fr. 51 como el final del fr. 50, apenas citado. El editor J.H. Declerck prefiere situarlas al principio de este fr. 51 (yo albergo mis

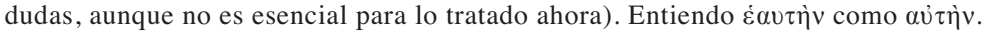

(39) Cf. Alessandro di Afrodisia. L'anima, a cargo de P. Accatino y P. Donini, Bari 1996, pp. 22-24.

(40) Fr. 128, p. 189. 
el hombre formado a partir del alma y del cuerpo, este es Samuel, el hombre

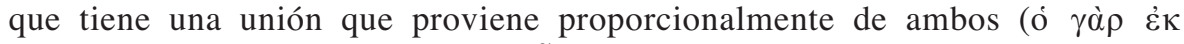

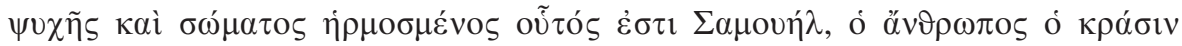

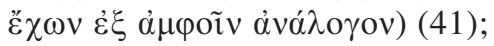

entendiendo que lo corpóreo es sensible y lo incorpóreo invisible, sin excepción:

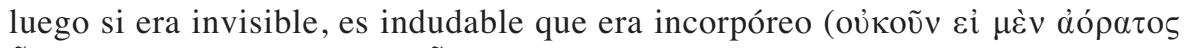

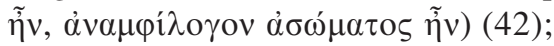

y defendiendo la cohabitación del espíritu divino y del alma con el cuerpo que habilita y perfecciona al hombre convirtiéndolo en templo santo e inmaculado:

así pues, si precisamente él dijo que el que proviene del género humano ha subido -él solo entre todos- hasta el cielo, y, de nuevo, ha descendido desde allí hasta aquí, y, aunque esté aquí, reside en el cielo, se deduce que el hombre, gracias a la virtud del alma ( $\psi v \chi \tilde{\eta} \varsigma \alpha \dot{\alpha} \rho \tau \tilde{\eta})$, realizó excelentemente estas cosas. En efecto, la santa alma de Cristo, que cohabita con el Logos divino, habita en todas las cosas en su conjunto, y ha llegado hasta el cielo más alto, hasta donde ningún otro de los hombres ha llegado. Y estas cosas se aplican también a la

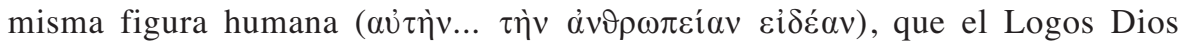

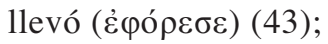

así como la dignidad de la naturaleza divina no sujeta a las pasiones ni a las intenciones, como lo muestra el descenso de Cristo al Hades:

no entendió, en efecto, que por ser Dios, no se encontraba presente arriba tanto

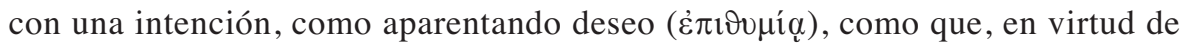

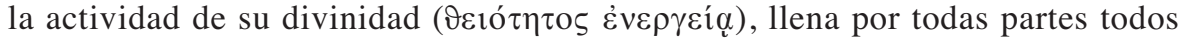
los lugares y cada uno lo más posible (44).

Sin embargo, después de todo lo examinado, hay unos elementos extraños al mundo aristotélico que nos impiden alistar sin más a Eustacio en un autor influido por el aristotelismo imperial. Estos, resumiéndolos en tres, son los siguientes: la definición de alma como espíritu, aplicándole el término preciso de pneuma; la aceptación de mezcla para el alma, e incluso para el nous, en términos de mixis o krasis; una cierta inmanencia de lo divino que está presente en todo lugar salvando su pureza y que no puede ser, por otro lado, circunscrito a ninguno en concreto.

Alguno podría apuntar que todo esto son trazas estoicizantes, y es verdad. Por otro lado, hemos visto la imposibilidad de atribuir a Eustacio bases estoicas. Estaríamos tentados de quedarnos perplejos o de renunciar a precisar más, de no ser por la

(41) Cf. De engastrimytho 5, en Eustathii opera omnia, p. 11.

(42) Cf. De engastrimytho 5, en Eustathii opera omnia, p. 11.

(43) Cf. De engastrimytho 18, en Eustathii opera omnia, p. 39.

(44) Cf. De engastrimytho 19, en Eustathii opera omnia, p. 41. 
existencia de algún que otro testimonio de los ss. II y III que denuncian líneas aristotélicas comprometidas con términos y dogmas estoicos. En parte, determinados planteamientos de Aristóteles de Mitilene (45) (aristotélico del s. II d. C.), como algunos similares de adversarios anónimos sin mejor identificar de Alejandro de Afrodisia registrados en su De anima, podrían francamente venir en nuestra ayuda para favorecer el resultado de nuestro análisis:

Y los que dicen, sí, que el alma es forma del cuerpo, pero la convierten en uno de los sustratos corpóreos del animal, como el fuego, el aire u otro, no se percatan de que hacen de una parte de la materia la forma de la materia

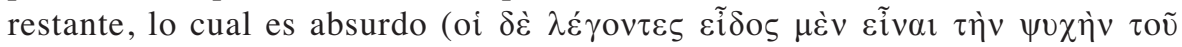

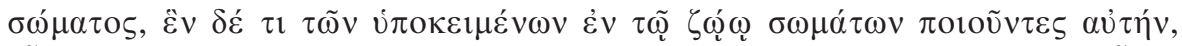

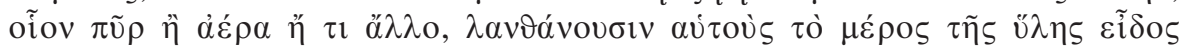

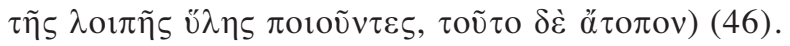

En efecto, tanto en Aristóteles de Mitilene como en los otros adversarios se defiende además una omnipresencia de lo divino, que escandaliza al Comentarista por excelencia de Aristóteles, es decir, a Alejandro. Más aún, en los adversarios anónimos hay una propensión a considerar al alma como fuego (con determinados planteamientos dispersos en los fragmentos auténticos y con el fr. 136 espurio, según Declerck, no según Simonetti, cf. infra), y, a pesar de retenerla forma del cuerpo, no dudar en admitirla también como resultante de la mezcla de los cuerpos (47).

\section{CONCLUSIÓN}

Si bien el estudio realizado no es, en absoluto, exhaustivo y los fragmentos de Eustacio recientemente editados (dentro de los cuales había hasta hace bien poco algunos inéditos) proporcionan aún bastantes más elementos de juicio, a falta de este trabajo necesario, podemos concluir acerca del sustrato filosófico de Eustacio de Antioquía que (a) está bastante lejos de los principales fundamentos platónicos, (b) tampoco armoniza de buen grado con los axiomas estoicos, (c) simpatiza bastante con las líneas de fuerza aristotélicas imperiales y (d) registra, no obstante, puntos fuertes irreconciliables con el aristotelismo más clásico, aunque no con determinadas corrientes del aristotelismo imperial -representadas por Aristóteles de Mitilene y criticadas por Alejandro de Afrodisia- de tendencia estoicizante.

Poniendo más límites a esta conclusión, diré que no pretendo identificar a Eustacio con estas últimas posiciones aludidas, ni mucho menos hacer de los adver-

(45) Cf. P. Moraux, L'Aristotelismo presso i Greci, vol. II/1, Milano 2000 (tr. de Der Aristotelismus bei den Griechen von Andronikosbis Alexander von Aphrodisia, Bd. II, Berlin 1984), pp. 390407.

(46) Cf. Alexandri Aphrodisiensis praeter commentaria scripta minora. De anima 19, 21-24, ed. I. Bruns [Commentaria in Aristotelem Graeca, suppl. 2.1], Berlin 1887. Comentado por P. Accatino y P. Donini en Alessandro di Afrodisia. L'anima, Bari 1996, pp. 137-139.

(47) Cf. Alexandri Aphrodisiensis de anima 19-20. 
sarios del Comentarista una secta cristiana, sino tan solo mostrar la cercanía y la afinidad. De ser cierta esta conclusión, cabría pensar también en ser más cautos a la hora de presentar las relaciones del aristotelismo con el cristianismo en los primeros siglos.

No fue, ciertamente, la línea más victoriosa después de todo. Tampoco, y quizás por ello, ha quedado mucha huella en las fuentes que tenemos a nuestra disposición, pero tal vez habrá que agradecer siempre a la línea antioquena haber sido la única capaz de frenar los excesos de la tradición alejandrina. No supo hacerlo tal vez con el vigor con que, a mi juicio, lo habrían hecho otros antioquenos y asiáticos de primera hora (pienso en Ignacio, Teófilo, Ireneo...), y sus lagunas las señalaron con acierto los alejandrinos, pero supo ser esta línea antioquena el contrapeso necesario para que la línea resultante no se apartara de la fe de la Iglesia.

\section{RESUMEN}

La reciente publicación de la edición crítica en el Corpus Christianorum de la obra de Eustacio, donde se da cuenta en detalle de las tradiciones manuscritas tanto griega como latina y siríaca, "debería suponer un estímulo para que Eustacio ocupe el lugar que merece en la historia del dogma, en la controversia arriana, en la tradición llamada antioquena". A partir de esta constatación, en la cual encontramos contenida implícitamente la motivación del autor, la presente investigación se propone identificar las corrientes filosóficas paganas que influyeron en el pensamiento de Eustacio, apartándose de lo estrictamente teológico a fin de sentar las bases para una comprensión integral de su obra. Con esta intención, el autor hace un camino en el cual confronta al Padre Antioqueno con platónicos, de los cuales está bastante lejano, a su juicio; con estoicos, con los cuales "tampoco armoniza de buen grado", y finalmente, con el aristotelismo tanto clásico, con el cual posee puntos irreconciliables, como con ciertas corrientes imperiales de este, criticadas por Alejandro de Afrodisia, y con las cuales Eustacio simpatiza bastante.

Aunque el autor no pretende identificar al Padre investigado con las posiciones aludidas, de todas formas quiere dejar clara su cercanía y afinidad a tales corrientes de pensamiento, conclusión, que de ser cierta, haría "pensar también en ser más cautos a la hora de presentar las relaciones del aristotelismo con el cristianismo de los primeros siglos".

\section{ABSTRACT}

The recent publication in the critical edition of the Corpus Christianorum of the work of Eustatius, wherein is found a detailed exposition of the Greek as well as the Latin and Syriac manuscript traditions, "ought to provide a stimulus so that Eustatius can occupy the place he deserves in the history of dogma, in the Arian controversy, in the tradition called Antiochene." From the starting point of this attestation, in which we find implicitly contained the motivation of the author, the present investigation proposes to identify the pagan philosophical currents that influenced Eustatius' thought, distancing himself from the strictly theological in order to establish the foundations for a holistic understanding of his work. With this intention, the author sets down a path by which he can confront the Antiochene Father with the Platonists, from whom he is at a good distance, in his judgement; with the Stoics, with whom "he doesn't harmonize to any large degree, either;" and, finally, with Aristotelianism, both classic-with which he possesses irreconcilable points-and in certain imperial currents, criticized by Alexander of Aphrodisia, and with which Eustatius sympathizes substantially. 
Although the author does not intend to identify his researched subject with the positions mentioned above, in any case he wants to make clear his proximity and affinity to such currents of thought, a conclusion which, if true, would make others "also consider being more cautious at the moment of presenting the relationship between Aristotelianism and Christianity of the first centuries". 